Milk Science

and Biotechnology

\title{
Functionality of Dairy Foods on Osteoporosis
}

\author{
Yong-II Moon', Sunho Lee ${ }^{2}$, Sangnam $\mathrm{Oh}^{3}$ and ${ }^{*}$ Younghoon $\mathrm{Kim}^{3}$ \\ ${ }^{1}$ Dept. of Animal Source Foods, Woosuk University, Wanju, Korea \\ 2Division of Food Bioscience and Technology, College of Life Sciences and Biotechnology, Korea University, Seoul, Korea \\ ${ }^{3}$ Dept. of Animal Science and Institute of Milk Genomics, Chonbuk National University, Jeonju, Korea
}

\begin{abstract}
Osteoporosis is a systemic skeletal disease characterized by decreased bone mass, which results in a markedly increased risk of traumatic fractures. This disease is a worldwide health problem with a high prevalence. Recently, various dietary components have been found to minimize the risk of developing osteoporosis through their ability to stimulate bone formation and optimize bone health. Among them, probiotics and fermented milk can have beneficial effects to human health. Bioactive compounds derived from probiotics in fermented milk can especially modulate physiological functions related to bone health. Here, we review the evidence to support these insights into newly found functionality of dairy foods for osteoporosis prevention.
\end{abstract}

\section{Keywords}

dairy foods, osteoporosis, probiotics, fermented milk

\section{Probiotics}

Definitions of the term "probiotic" have been used over a few decades, but one of the recent interpretations of the word was derived by the Food and Agriculture Organization of the United Nations-World Health Organization (FAO-WHO), and it is endorsed by the International Scientific Association for Probiotics and Prebiotics. They mentioned that: "Live microorganisms, which when administered in adequate amounts, confer a health benefit on the host". In recent, it is getting accepted more and more by consumers which live lactic acid bacteria does exert health benefits when they get eaten. In addition, it is also becoming recognized that not all probiotic bacteria are equal (Dekker et al., 2007). It should also be added that lactic acid bacteria does taking a major role in human intestine as probiotics. Since the early studies of Metchnikoff of the favorable effects of soured milk products in humans, the most beneficial part of the intestinal microbiota has been suggested to be lactic acid bacteria. Moreover, Lactic acid bacteria are treated as the easiest findable commercial probiotics preparations still in these years. For these reasons, studies of lactic acid bacteria are becoming an important part which related with many people's health. The various probiotics group were evaluated that Lactobacillus acidophilus, L. salivarius, L. casei, L. plantarum, L. fermentum, L. reuteri, Pediococcus acidilactici and Bifidobacterium spp. (modified from Salminen et al., 2004, Table 1). The many commercialized probiotics strains have been identified and useful for dairy products such as fermented milk in the market (modified from Yeung et al., 1999, Table 2).

The probiotic products traditionally incorporate intestinal species of Lactobacillus because of their long history of safe use in the dairy industry and their natural presence in the human

This is an Open Access article distributed under the terms of the Creative Commons Attribution Non-Commercial License (http://creativecommons.org/licenses/ by-nc/3.0) which permits unrestricted non-commercial use, distribution, and reproduction in any medium, provided the original work is properly cited. 
Table 1. Microorganisms usually connected with beneficial probiotic and dietary properties in cultured milks

\begin{tabular}{cl}
\hline Probiotics & \multicolumn{1}{c}{ Strains } \\
\hline $\begin{array}{c}\text { Bifidobacterium } \\
\text { species }\end{array}$ & $\begin{array}{l}\text { Bifidobacterium longum } \\
\text { Bifidobacterium bifidum } \\
\text { Bifidobacterium infantis } \\
\text { Bifidobacterium animalis } \\
\text { Bifidobacterium lactis }\end{array}$ \\
\hline Pediococcus & Pediococcus acidilactici \\
species & Lactobacillus delbruekii supsp. bugaricus \\
& Lactobacillus acidophilus \\
& Lactobacillus casei \\
Lactobacillus & Lactobacillus paracasei \\
speices & Lactobacillus reuteri \\
& Lactobacillus rhamnosus \\
\hline Propionibacterium & Propionibacterium freudenreichii \\
species & Enterococcus faecium \\
Enterococcus & previous name Streptococcus faecium)
\end{tabular}

intestinal tract, which is known to contain a myriad of microbes, collectively called the microbiota (Tannock, 1998; Falk et al., 1998). Members of the Bifidobacterium have more recently been added to foods for probiotic purposes, probably encouraged by the discovery of their consistent presence as part of the normal microbiota of the human intestine (Tannock, 1999). The desirable effects on human health include antagonistic activity against pathogens, anti-allergic effects and other effects on the immune system. As evidence accumulates for their beneficial effects on human health, these bacteria are increasingly being included as functional ingredients, particularly in dairy products such as yoghurts and other fermented milks (Fig. 1). Nevertheless, there are some reasonable skeptical opinions among the scientific community about probiotic effects; because, the mechanistic details which underlying probiotic effects are just simply unknown. Although the effects of the gut commensal microbiota are necessary for development and maintenance of normal

Table 2. Characterized of commercial probiotic strains

\begin{tabular}{|c|c|}
\hline Strain & Source \\
\hline Lactobacillus acidophilus NCFM & Rhodia, Inc. (Madison, Wis.) \\
\hline Lactobacillus acidophilus DDS-1 & Nebraska Cultures, Inc. (Lincoln, Neb.) \\
\hline Lactobacillus acidophilus SBT-2062 & Snow Brand Milk Products Co., Ltd. (Tokyo, Japan) \\
\hline Lactobacillus acidophilus LA-1 & Chr. Hansen, Inc. (Milwaukee, Wis.) (same as strain LA-5 sole in Europe) \\
\hline Lactobacillus casei Shirota & Yakult (Tokyo, Japan) \\
\hline Lactobacillus casei Immunitas & Danone (Paris, France) \\
\hline Lactobacillus fermentum RC-14 & Urex Biotech (London, Ontario, Canada) \\
\hline Lactobacillus johnsonii La1 & Nestle' (Lausanne, Switzerland) (same as Lj1) \\
\hline Lactobacillus paracasei CRL 431 & Chr. Hansen, Inc. (Milwaukee, Wis.) \\
\hline Lactobacillus plantarum 299V & Probi AB (Lund, Sweden) (same as MM2) \\
\hline Lactobacillus reuteri SD2112 & Biogaia (Raleigh, N.C.) \\
\hline Lactobacillus thamnosus GG & Valio Dairy (Helsinki, Finland) \\
\hline Lactobacillus thamnosus GR-1 & Urex Biotech (London, Ontario, Canada) \\
\hline Lactobacillus thamnosus 271 & Probi AB (Lund, Sweden) \\
\hline Lactobacillus rhamnosus LB21 & Essum AB (Umea, Sweden) \\
\hline Lactobacillus salivarius UCC118 & University College (Cork, Ireland) \\
\hline Lactobacillus lactic L1A & Essum AB (Umea, Sweden) \\
\hline Bifidobacterium lactic $\mathrm{Bb}-12$ & Chr. Hansen, Inc. (Milwaukee, Wis.) \\
\hline Bifidobacterium longum BB536 & Morinaga Milk Industry Co., Ltd. (Zama-City, Japan) \\
\hline Bifidobacterium longum SBT-2928 & Snow Brand Milk Products Co., Ltd. (Tokyo, Japan) \\
\hline Bifidobacterium breve strain Yakult & Yakult (Tokyo, Japan) \\
\hline
\end{tabular}






Fig. 1. Proposed health benefits stemming from probiotic consumption (adapted from Saarela et al., 2002)

health, the effects of individual members on our health are still not understood even though the fact has been recognized for decades.

\section{Fermented Milk}

Milk is a white liquid produced by the mammary glands of mammals. It is the primary source of nutrition for young mammals until they are able to digest other types of foods. Early-lactation milk contains colostrum, which carries the mother's antibodies to the baby, can prevent a baby from the risk of many diseases. Milk is an important food with many nutrients (Pehrsson et al., 2000). Milk contains nutrients which required for the growth and development of the neonate. All milks contain specific proteins and fats which designed to make digest easier, and also the milks contains lactose, minerals, vitamins, and other components which taking an important roles. These are organized as follows: lipids in emulsified globules coated with a membrane, proteins in colloidal dispersion as micelles, and most minerals and all lactose in true solution (Jensen et al., 1991). In many cultures of the world, humans continue to drink milk from other animals (especially cattle, goats and sheep) as a dairy foods. Among them, fermented milk products, also known as cultured dairy foods, cultured dairy products, or cultured milk products, are dairy foods that have been fermented with lactic acid bacteria such as Lactobacillus, Lactococcus, and Leuconostoc. The fermentation process increases the shelf-life of the product, as well as adds to the taste and improves the digestibility of milk. While numerous researchers (Taranto et al., 1998; Lee et al., 1999; Danone, 2001) have suggested that lactic culture and their fermented products provide several nutritional and therapeutic benefits to the consumers. The majority of the papers suggest that the potential benefit following the consumption of fermented dairy products containing viable lactic acid bacteria (Deeth and Tamime., 1981; Fernandes et al., 1987; Gilliland, 1990; Fujiwara et al., 1997; Gill and Guarner, 2004) is primarily attributable to the favorable alteration in GI micro-ecology.

\section{Osteoporosis}

Osteoporosis defined by the working group of the World Health Organization (WHO) as a bone density T score at or $<2.5$ SD below normal peak values for young adults. The osteoporosis primary definition is a skeletal disorder of post-menopausal women or of old people. But, recently definition is a systemic skeletal disease characterized by low bone mass and the micro architectural deterioration of bone tissue, with a consequent increase in bone fragility and susceptibility to fracture (Marcus et al., 2001). Osteoporosis is mainly a primary disease. With the increase of age, it is progressive and irreversible. Also, osteoporosis can cause or be complicated with lumbodorsal pain, malignant tumors, and other diseases. Therefore, it is not only a medical concern but also a serious health care and social problem. Furthermore, given the clear sex-related difference in the incidence of this disease, such interventions should be readily undertaken for women, and especially for postmenopausal women whose bone mass rapidly decreases (Ylikorkala, 2008; Ohta et al., 1999; Dane et al., 2008; Al-Azzawi, 2008). Since osteoporosis is influenced by genetic and environmental factors such as diet and lifestyle, it is important to develop strategies and recommendations for both the treatment and prevention of osteoporosis. In recent years, nutrients have 
received considerable interest because of their potential to prevent or minimize the risk of developing osteoporosis (Weber, 1999; Cashman, 2007). Osteoporosis could be divided into two distinct syndromes (Type I and Type II osteoporosis) that different symptoms such as in regional bone mineral density (BMD), fracture patterns, hormone changes and mechanism. Type I osteoporosis typically affects women within 15 20 years after menopause. This type characterized by fractures occurring at sites that contain relatively large amount of cancellous bone therefore increased tooth loss occurs in type I osteoporosis. And type II occurs in both sex, but is twice as common in women as in men. Type II osteoporosis is characterized vertebral fracture that hip fracture, pelvis, proximal humorous and proximal tibia (Riggs et al., 2001).

Osteoporosis disease was characterized by low bone mass and micro-architectural deterioration of bone tissue, leading to enhanced bone fragility and a consequent increase in fracture. The bone loss results from imbalance between the activities of osteoblast and osteoclast that leads to uncoupling of bone formation and bone resorption. Bone homeostasis is maintained by a balance between bone formation by osteoblasts and bone resorption by osteoclasts, respectively (Sprague, 2000). Osteoblasts are derived from a multi-potential mesenchymal cell that can alternatively differentiate also into marrow stromal cells or adipocytes (Aubin, 2001; Silvernnoinen et al., 1995). The signals that are involved for the development of osteoblasts from mesenchymal progenitor cells are not fully understood (Walsh et al., 2006; Frei et al., 2006). Wnt signalling through Wnt10b is involved in the fate decision in differentiating mesenchymal progenitor cells between adipocytes and osteoblasts (Bennett et al., 2005). Osteoclasts are multinucleated macrophage-like giant cells that resorb bone (Teitelbaum, 2000). They are hematopoietic in origin and derive from myeloid precursors that also give rise to macrophages and dendritic cells. Signals that control osteoclasts to form and resorb bone involve several transcription factors and cytokines which are discussed later in detail (Raisz, 2005, Fig. 2). The critical role of nuclear factor kappa B (NFkB) in osteoclast formation has been demonstrated in NFkB1 and NFkB2 knockout mice that showed osteopetrosis caused by a defect in osteoclast development (Iotsoval et al., 1997). To remove organic components of bone, osteoclasts produce several



Fig. 2. Bone remodeling under physiological conditions (adapted from Tilg et al., 2008)

enzymes such as cathepsin. Osteoclasts are highly motile, move across the bone surface, and resorb large areas of bone (Teitelbaum, 2000; Lawrence, 2005, Fig. 3). They died by apoptosis regulated by several paracrine acting cytokines. Inflammation-related osteoporosis is driven by activation of osteoclasts and therefore this cell type is of critical importance.

Bone formation and resorption are 'coupled' locally by mechanisms not fully understood, that is, when one goes up or down the other usually follows. But resorption is much faster than formation (it takes at least three months to rebuild bone resorbed in 2-3 weeks). Thus, increased resorption, even then accompanied by coupled increase formation, can cause bone loss owing to these kinetic differences; for instance, in estrogen deficiency or hyperparathyroidism. Multiple coupling factors attempt to maintain this servo system at its physiological (homeostatic) steady state (Fig. 4). Bone formation stimulatory factors released from the matrix during resorption, including insulin-like growth factor and transforming growth factor (TGF)- $\beta$, may serve this function. Several factors, such as PTH, PGE, fibroblast growth factor, TGF- $\beta$ and even RANK ligand, have been shown to stimulate both resorption and formation. Mechanical effects on bone could also couple 


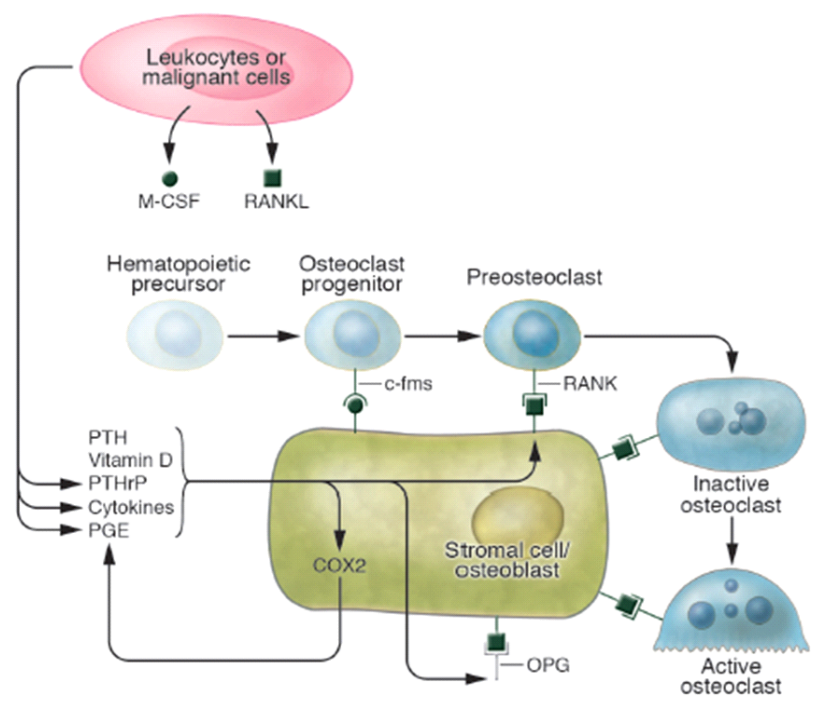

Fig. 3. Regulation of osteoclast formation and activity (adapted from Lawrence, 2005).

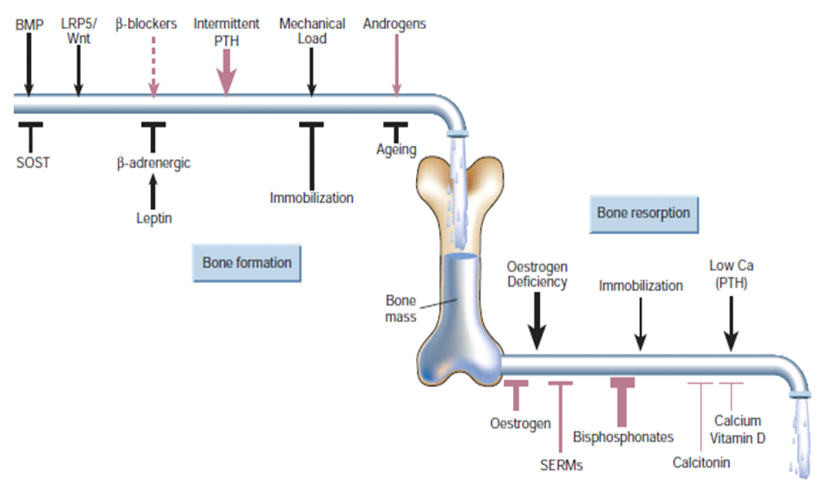

Fig. 4. Various factors of affecting on bone formation and resorption (adapted from Harada and Rodan, 2003).

resorption to formation, as weakening of the bone as a result of resorption should engender corrective bone formation (Harada and Rodan, 2003).

Lifestyle prevention of osteoporosis is in many aspects inversions from potentially modifiable risk factors. As tobacco smoking and unsafe alcohol intake have been linked with osteoporosis, smoking cessation and moderation of alcohol intake are commonly recommended in the prevention of osteoporosis. Many other risk factors, some modifiable and others not modifiable, such as genetic, may be involved in osteoporosis (Davis et al., 2010). Whether or not calcium (with or without vitamin $\mathrm{D}$ ) is effective in preventing osteoporosis is controversial. A 2007 review supported its use for pre- vention in people over the age of 50 years (Tang et al., 2007). A review and draft recommendation by the United States Preventive Services Task Force in 2012 found insufficient evidence to determine risk verses harm from supplementation in women before menopause or in men, so does not recommend it for this group (Vitamin D and Calcium Supplementation to Prevent Cancer and Osteoporotic Fractures in Adults: U.S. Preventive Services Task Force Recommendation Statement, 2012). People at risk for osteoporosis (e.g. steroid use) are generally treated with vitamin D and calcium supplements and often with bisphosphonates. Vitamin D supplementation alone does not prevent fractures, and needs to be combined with calcium (Sahota, 2010; The DIPART group, 2010). Estrogen replacement therapy remains a good treatment for prevention of osteoporosis, but is not recommended yet unless other indications for its use are present, as well. There is uncertainty and controversy about whether estrogen should be recommended in women in the first decade after the menopause. In hypogonadal men, testosterone has been shown to give improvement in bone quantity and quality, but, as of 2008, no studies of the effects on fractures or in men with a normal testosterone level have been reported (Ebeling, 2008).

The clinically useful bisphosphonates are synthetic analogues of inorganic pyrophosphate, an endogenous regulator of bone turnover that inhibits bone resorption and mineralization in vitro (Fleisch, 1991). All bisphosphonates have a high affinity for hydroxyapatite but, unlike pyrophosphate, are resistant to metabolism by endogenous phosphatases (Fleisch, 1991; Schenk et al., 1986). Bisphosphonates are capable of inhibiting bone mineralization at roughly equivalent doses; however, their potencies for the inhibition of bone resorption depend on the unique chemical structure of their side chains (Shinoda et al., 1983). The four-carbon amino side chain of alendronate conveys a very high potency, which in turn permits effective inhibition of osteoclast-mediated bone resorption at doses that do not impair bone mineralization, 6 even with daily doses, which is not the case with etidronate (Marcus, 1993; Axelrod and Teitelbaum, 1994). Treatment with alendronate specifically inhibits increased bone resorption and thereby normalizes the rate of bone turnover (Garnero et al., 1994). Preclinical evaluations of alendronate in animals with osteoporosis have documented greater bone strength in accordance with 
increased bone mass, (Guy et al., 1993; Balena et al., 1993) indicating the normal quality of alendronate- treated bone. Iliac-crest biopsies in patients treated with alendronate for up to three years show normal bone without evidence of mineralization defects (Arlot et al., 1995).

\section{Dairy Products and Osteoporosis}

Dairy products such as milk have been proposed as a nutritional food that aids in the prevention of osteoporosis due to its bioavailable calcium content (Silverwood, 2003). Lactoferrin (iron-binding glycoprotein) is a non-enzymatic antioxidant found in the whey fraction of milk (Marshall, 2004). Lactoferrin has functional bone metabolism that is promotes the osteoblast cell growth and reduces osteoclast differentiation and resorption activity (Cornish, 2004; Lorget et al., 2002). In vitro and in vivo determined milk basic protein (MBP) has the ability to stimulate proliferation and differentiation of osteoblastic cells as well as suppress bone resorption (Takada et al., 1997a; Toba et al., 2000). MBP is prepared from fractionated whey through cation exchange resin. In vivo studies on rats determined that both whey protein and fractionated whey protein had the ability to increase femoral bone strength in ovariectomized rats (Takada et al., 1997b; Kato et al., 2000). Recently reports, the fermented milk by $\mathrm{L}$. helviticus contains small peptides such as isoleucyl-proly-proline (IPP) and valyl-prolyl-proline (VPP) (Nakamura et al., 1995). This small peptides are inhibits the angiotensin converting enzyme (ACE). Fermented milk containing IPP and VPP long term fed on rats has been lowered the blood pressure (Sipola et al., 2002). So this fermented milk by L. helviticus affects calcium accumulation on osteoblasts (Narva et al., 2004). In conclusion, bioactive compounds from dairy foods including fermented milk can provide new functionality on prevention of osteoporosis.

\section{Acknowledgments}

This research was supported by the High Value-Added Food Technology Development Program of the Korea Institute of Planning and Evaluation for Technology in Food, Agriculture, Forestry, and Fisheries (iPET), the Ministry for Food, Agriculture, Forestry, and Fisheries of the Republic of Korea (11113703-3-SB010).

\section{References}

1. Al-Azzawi F. 2008. Prevention of postmenopausal osteoporosis and associated fractures: Clinical evaluation of the choice between estrogen and bisphosphonates. Gynecol. Endocrinol. 24:601-609.

2. Arlot, M. C., Meunier, P. J. and Chavassieux, P. 1995. Effects of long-term alendronate treatment for postmenopausal osteoporosis on bone histomorphometry. J. Bone Miner. Res. 10:1:S199.

3. Aubin, J. E. 2001. Regulation of osteoblast formation and function. Rev. Endocr. Metab. Disord. 2:81-94.

4. Axelrod, D. W. and Teitelbaum, S. L. 1994. Results of long-term cyclical etidronate therapy: Bone histomorphometry and clinical correlates. J. Bone Miner. Res. 9:1:S136.

5. Balena, R., Toolan, B. C., Shea, M., Markatos, A., Myers, E. R., Lee, S. C., Opas, E. E., Seedor, J. G., Klein, H., Frankenfield, D., Quartuccio, H., Fioravanti, C., Clair, J., Brown, E., Hayes, W. C. and Rodan, G. A. 1993. The effects of 2-year treatment with the aminobisphosphonate alendronate on bone metabolism, bone histomorphometry, and bone strength in ovariectomized nonhuman primates. J. Clin. Invest. 92:2577-2586.

6. Bennett, C. N., Longo, K. A., Wright, W. S., Suva, L. J., Lane, T. F., Hankenson, K. D. and MacDougald O. A. 2005. Regulation of osteoblastogenesis and bone mass by Wnt10b. Proc. Natl. Acad. Sci. 102:3324-3329.

7. Cashman, K. D. 2007. Diet, nutrition, and bone health. J. Nutr. 137:2507S-2512S.

8. Cornish, J. 2004. Lactoferrin promotes bone growth BioMetals. 17:331-335.

9. Dane, C., Dane, B., Cetin, A. and Erginbas, M. 2008. Effect of risedronate on biochemical marker of bone resorption in postmenopausal women with osteoporosis or osteopenia. Gynecol. Endocrinol. 24:207-213.

10. Danone. 2001. Fermented foods and healthy digestive functions. France: Danone Publications, John Libbey Euro text.

11. Davis, S., Oliver, A., Goeckeritz, B. and Sachdeva, A. 2010. All about osteoporosis: A comprehensive analysis. J. Muscoskel. Med. 27:149-153.

12. Deeth, H. C. and Tamime, A. Y. 1981. Yogurt, nutritive and therapeutic aspects. J. Food Prot. 44:78-86. 
13. Dekker, J., Collett, M., Prasad, J. and Gopal, P. 2007. Functionality of probiotics potential for product development. Forum Nutr. 60:196-208.

14. Ebeling, P. R. 2008. Clinical practice. Osteoporosis in men. N. Engl. J. Med. 358:1474-1482.

15. Falk, P. G., Hooper, L. V., Midtvedt, T. and Gordon, J. F. 1998. Creating and maintaining the gastrointestinal ecosystem: what we know and need to know from gnotobiology. Microbiol. Mol. Biol. Rev. 62:1157-1170.

16. Fernandes, C. F., Shahani, K. M. and Amer, M. A. 1987. Therapeutic role of dietary lactobacilli and lactobacillic fermented dairy products. FEMS Microbiol. Rev. 46:343356.

17. Fleisch, H. 1991. Bisphosphonates: Pharmacology and use in the treatment of tumor-induced hypercalcaemic and metastatic bone disease. Drugs. 42:919-944.

18. Frei, P., Fried, M., Hungerbühler, V., Rammert, C., Rousson, V. and Kullak-Ublick, G. A. 2006. Analysis of risk factors for low bone mineral density in inflammatory bowel disease. Digestion 73:40-46.

19. Fujiwara, S., Hashiba, H., Hirota, T. and Forstner, J. F. 1997. Proteinaceous factor(s) in culture supernatant fluids of Bifidobacteria which prevents the binding of enterotoxigenic Escherichia coli to gangliotetraosylceramide. Appl. Environ. Microbiol. 63:506-512.

20. Garnero, P., Shih, W. J., Gineyts, E., Karpf, D. B. and Delmas, P. D. 1994. Comparison of new biochemical markers of bone turnover in late postmenopausal osteoporotic women in response to alendronate treatment. J. Clin. Endocrinol. Metab. 79:1693-1700.

21. Gill, H. S. and Guarner, F. 2004. Probiotics and human health: A clinical perspective. Postgrad. Med. J. 80:516-526.

22. Gilliland, S. E. 1990. Health and nutritional benefits from lactic acid bacteria. FEMS Microbiol. Rev. 87:175-188.

23. Guy, J. A., Shea, M., Peter, C. P., Morrissey, R. and Hayes, W. C. 1993. Continuous alendronate treatment throughout growth, maturation, and aging in the rat results in increases in bone mass and mechanical properties. Calcif Tissue Int. 53:283-288.

24. Harada, S. and Rodan, G. A. 2003. Control of osteoblast function and regulation of bone mass. Nature 423:349-355.

25. Iotsoval, V., Caamañol, J., Loy, J., Yang, Y., Lewin, A. and Bravo, R. 1997. Osteopetrosis in mice lacking NF-kappaB1 and NF-kappaB2. Nat. Med. 3:1285-1299.

26. Jensen, R. G., Ferris, A. M. and Lammi-Keefe, C. J. 1991. The composition of milk fat. J. Dairy Sci. 74:3228-3243.

27. Kato, K., Toba, Y. and Matsuyama, H. 2000. Milk basic protein enhances the bone strength in ovariectomized rats. J. Food Biochem. 24:467-476.

28. Lawrence, G. R. 2005. Pathogenesis of osteoporosis: Concepts, conflicts, and prospects. J. Clin. Invest. 115:3318-3325.

29. Lee, Y. K., Nomoto, K., Salminen, S. and Gorbach, S. L. 1999. Handbook of probiotics. New York: John Wiley \& Sons.

30. Loget, F., Clough, J., Oliveira, M., Daury, M. C., Sabokbar, A. and Offord, E. 2002. Lactoferrin reduces in vitro osteoclast differentiation and resorbing activity. Biochem. Biophys. Res. Commun. 296:261-266.

31. Marcus, R. 1993. Cyclic etidronate: Has the rose lost its bloom? Am. J. Med. 95:555-556.

32. Marshall, K. 2004. Therapeutic applications of whey protein. Altern. Med. Rev. 9:136-156.

33. Nakamura, Y., Yamamoto, N., Sakai, K., Okubo, A., Yamazaki, S. and Takano, T. 1995. Purified and characterization of angiotensin I-converting enzyme inhibitors form sour milk. J. Dairy Sci. 78:777-783.

34. Narva, M., Collin, M., Lamberg-Allardt, C., Karkkainen, M., Poussa, T., Vapaatalo, H. and Korpela, R. 2004. Effects of long-term intervention with Lactobacillus helviticus-fermented milk on bone mineral density and bone mineral content in growing rats. Ann. Nut. Metabol. 48:228-234.

35. Ohta, H., Komukai, S., Makita, K., Masuzawa, T. and Nozawa, S. 1999. Effects of 1-year ipriflavone treatment on lumbar bone mineral density and bone metabolic markers in postmenopausal women with low bone mass. Horm Res. 51:178-183.

36. Pehrsson, P. R., Haytowitz, D. B., Holden, J. M., Perry, C. R. and Beckler, D. G. 2000. USDA's National food and nutrient analysis program: Food sampling. J. Food Compos. Anal. 13:379-389.

37. Raisz, L. G. 2005. Pathogenesis of osteoporosis: Concepts, conflicts, and prospects. J. Clin. Invest. 115:3318-3325.

38. Riggs, B. L., Khosla, S. and Melton, L. J. III. 2001. The type I/type II model for involutional osteoporosis. Osteoporosis. Academic Press, San Diego.

39. Saarela, M., Lähteenmäki, L., Crittenden, R., Salminen, 
S., Mattila-Sandholm, T. 2002. Gut bacteria and health foods - the European perspective. Int. J. Food Microbiol. 78: 99-117.

40. Sahota, O. 2010. Reducing the risk of fractures with calcium and vitamin D. BMJ. 340:b5492.

41. Salminen, S., Wright, A. V. and Ouwehand, A. 2004. Lactic acid bacteria, microbiological and functional aspects. New York, NY.

42. Schenk, R., Eggli, P., Fleisch, H. and Rosini, S. 1986. Quantitative morphometric evaluation of the inhibitory activity of new minobisphosphonates on bone resorption in the rat. Calcif Tissue Int. 38:342-349.

43. Shinoda, H., Adamek, G., Felix, R., Fleisch, H., Schenk, R. and Hagan, P. 1983. Structureactivity relationships of various bisphosphonates. Calcif Tissue Int. 35:87-99.

44. Silvennoinen, J. A., Karttunen, T. J., Niemelä, S. E., Manelius, J. J and Lehtola, J. K. 1995. A controlled study of bone mineral density in patients with inflammatory bowel disease. Gut. 37:71-76.

45. Silverwood, B. 2003. Building healthy bones. Paediatr Nurs. 15:27-29.

46. Sipola, M., Finckenberg, P., Korpela, R., Vapaatalo, H. and Nurminen, M-L. 2002. Effect of long-term intake of milk products on blood pressure in hypertensive rats. J. Dairy Res. 69:103-111.

47. Sprague, S. M. 2000. Mechanism of transplantation-asscociated bone loss. Pediatr Nephrol. 14:650-653.

48. Takada, Y., Kobayashin, N., Kato, K., Matsuyama, H., Yahiro, M. and Aoe, S. 1997b. Effects of whey protein on calcium and bone metabolism in ovariectomized rats. J. Nut. Sci. Vitaminol. 43:199-210.

49. Takada, Y., Kobayashin, N., Matsuyama, H., Kato, K, Yamamura, J., Yahiro, M., Kumegawa, M. and Aoe, S. 1997a. Whey protein suppresses the osteoclast mediated bone reseption and osteoclast cell formation. Int. Dairy J. 7:821-825.

50. Tang, B. M., Eslick, G. D., Nowson, C, Smith, C. and Bensoussan, A. 2007. Use of calcium or calcium in combination with vitamin $\mathrm{D}$ supplementation to prevent fractures and bone loss in people aged 50 years and older: A meta-analysis. Lancet. 370:657-666.

51. Tannock, G. W. 1998. Studies of the intestinal microflora: A prerequisite for the development of probiotics. Int. Dairy. J. 8:527-533.

52. Tannock, G. W. 1999. A fresh look at the intestinal microflora. In Probiotics: A critical review. Edited by Tannock GW. Norfolk, UK: Horizon Scientific Press. 5-14.

53. Taranto, M. P., Medici, M., Perdigon, G., Ruiz Holgado, A. P. and Valdez, G. F. 1998. Evidence for hypocholesterolemic effect of Lactobacillus reuteri in hypercholesterolemic mice. J. Dairy Sci. 81:2336-2340.

54. Teitelbaum, S. L. 2000. Bone resorption by osteoclasts. Science. 289:1504-1508.

55. The DIPART (vitamin D Individual Patient Analysis of Randomized Trials) Group, 2010. Patient level pooled analysis of 68500 patients from seven major vitamin D fracture trials in US and Europe. BMJ. 340, b5463.

56. Tilg, H., Moschen, A. R., Kaser, A., Pines, A. and Dotan, I. 2008. Gut, inflammation and osteoporosis: Basic and clinical concepts. Gut. 57:684-694.

57. Toba, Y., Takada, Y., Yamamura, J., Tanaka, M., Matsuoka, Y., Kawakami, H., Itabashi, A., Aoe, S. and Kumegawa, M. 2000. Milk basic protein: A novel protective function of milk against osteoporosis. Bone 27:403-408.

58. Vitamin D and Calcium Supplementation to Prevent Cancer and Osteoporotic Fractures in Adults: U.S. Preventive Services Task Force Recommendation Statement. United States Preventative Task Force. 2012.

59. Walsh, M. C., Kim, N., Kadono, Y., Rho, J., Lee, S. Y., Lorenzo, J. and Choi, Y. 2006. Osteoimmunology: Interplay between the immune system and bone metabolism. Annu. Rev. Immunol. 24:33-63.

60. Weber, P. 1999. The role of vitamins in the prevention of osteoporosis a brief status report. Int. J. Vitam. Nutr. Res. 69:194-197.

61. Ylikorkala, O. 2008. A more active role for gynecologists in the prevention of postmenopausal osteoporosis. Gynecol Endocrinol. 24:293-394. 